\title{
Post-release survival of juvenile silky sharks captured in a tropical tuna purse seine fishery
}

\author{
Melanie Rhiannon Hutchinson ${ }^{1, *}$, David George Itano ${ }^{2,3,4}$, Jeffrey Allen Muir ${ }^{2,3,5}$, \\ Kim Nicholas Holland ${ }^{1}$
}

\footnotetext{
${ }^{1}$ Department of Zoology, University of Hawaii, Hawaii Institute of Marine Biology, PO Box 1346 Kaneohe, Hawaii 96744, USA

${ }^{2}$ International Seafood Sustainability Foundation, 805 15th Street NW, Suite 650, Washington D.C. 20005, USA

${ }^{3}$ Pelagic Fisheries Research Program, University of Hawaii, Marine Science Building 312, Honolulu, Hawaii 96822, USA

${ }^{4}$ Present address: NOAA Inouye Regional Center, NMFS/PIR/PIRO/SFD, 1845 Wasp Blvd. Bldg. 176 Honolulu, Hawaii 96818, USA

${ }^{5}$ Present address: Hawaii Institute of Marine Biology, PO Box 1346 Kaneohe, Hawaii 96744, USA
}

\begin{abstract}
Juvenile silky sharks Carcharhinus falciformis comprise the largest component of the incidental elasmobranch catch taken in tropical tuna purse seine fisheries. During a chartered cruise on board a tuna purse seine vessel conducting typical fishing operations we investigated the post-release survival and rates of interaction with fishing gear of incidentally captured silky sharks using a combination of satellite linked pop-up tags and blood chemistry analysis. To identify trends in survival probability and the point in the fishing interaction when sharks sustain the injuries that lead to mortality, sharks were sampled during every stage of the fishing procedure. The total mortality rates of silky sharks captured in purse seine gear was found to exceed $84 \%$. We found survival to precipitously decline once the silky sharks had been confined in the sack portion of the net just prior to loading. Additionally, shark interactions recorded by the scientists were markedly higher than those recorded by vessel officers and the fishery observer. Future efforts to reduce the impact of purse seine fishing on silky shark populations should be focused on avoidance or releasing sharks while they are still free swimming.
\end{abstract}

KEY WORDS: Post-release survival $\cdot$ Bycatch $\cdot$ Silky shark $\cdot$ Fish aggregating device

\section{INTRODUCTION}

Nearly $82 \%$ of the total global tuna landings are consumed as a canned product, and the European Union and the United States are the largest consumers of canned tuna by far $(83 \%$ combined, Gilman \& Lundin 2008). The western and central Pacific Ocean (WCPO) tuna fishery is the largest volume tuna fishery in the world, where $69 \%$ of the total caught tuna is landed via purse seine fishing (Williams \& Terawasi 2013) and destined for a cannery. A significant amount of this purse seine fishing effort is focused on the use of drifting Fish Aggregating Devices (FADs) to increase catch rates and reduce search time (Dagorn et al. 2013). These FADs are often outfitted with sophisticated GPS and sonar buoys which inform the vessel of the FAD's proximity and a rough estimate of the biomass underneath it. The use of FADs in industrial-scale purse seine fishing is a contentious issue because they not only attract the target tuna species but also several other 'non-target' pelagic species. Bycatch rates of vulnerable species such as sharks, sea turtles (Watson et al. 2008) and juvenile bigeye tuna, Thunnus obesus (Fonteneau et al. 2000) are much higher at FADs than for fishing sets conducted on free-schools of tuna. Juvenile silky sharks Carcharhinus falciformis congregate around these drifting objects and become 
incidentally caught in purse seine nets targeting skipjack Katsuwonus pelamis and yellowfin tunas Thunnus albacares harvested for production of canned tuna products (Filmalter et al. 2011). In the WCPO FAD-associated purse seine fishery (where nets are set around a FAD), silky sharks compose $95 \%$ of the total elasmobranch bycatch (Lawson 2011). Shark catch rates are typically twice as high in FAD-associated sets versus unassociated or 'free school' fishing sets (Clarke et al. 2011). High juvenile silky shark catch rates have also been documented in FAD-associated tuna purse seine sets in the Eastern Pacific Ocean (Román-Verdesoto \& Orozco-Zoller 2005), the Atlantic Ocean (Amandè et al. 2010) and the Indian Ocean (Amandè et al. 2008). In the Indian Ocean, Poisson et al. (2014) demonstrated that postrelease survival among purse seine captured silky sharks was $<20 \%$.

The scientific committee to the Western Central Pacific Fisheries Commission (WCPFC) has raised concerns about silky shark bycatch rates in the FADassociated purse seine fishery because of declining catch rate trends and declines in median sizes despite increased fishing effort (Clarke 2011). Additionally, the WCPO stock assessment concluded the silky shark stock is overfished and that overfishing is currently occurring (Rice \& Harley 2013). These factors, in combination with the life history characteristics of elasmobranchs (e.g. slow growth, low reproductive output, late ages at maturity) may prevent silky shark populations from recovering from excessive fishing pressure. Furthermore, population demographic analyses have shown that high mortality on the juvenile life stages of elasmobranchs has the most profound effect on silky shark population growth or decline (Cortes 2002, Beerkircher et al. 2003, Román-Verdesoto 2014). It is predominantly juvenile silky sharks that are found in association with FADs, which makes this population more vulnerable to over-exploitation via this fishing modality.

Similar to most commercial tuna fisheries, sharks that are captured incidentally are typically discarded at sea (Worm et al. 2013). Discarded sharks are often released alive but several studies have shown that sharks may sustain injuries, both physical trauma from capture and handling, and physiological disturbances that can have immediate or prolonged effects resulting in mortality (eg. Skomal 2007, Skomal \& Mandelman 2012). Blood borne biochemical indicators of stress are increasingly being used to elucidate the post-release condition of discarded elasmobranchs captured in fisheries (eg. Moyes et al. 2006, Hight et al. 2007, Renshaw et al. 2012). Physiological effects typically involve respiratory and metabolic acidosis, changes in the osmotic structure of the blood plasma, hemodilution and elevated glucose levels (Renshaw et al. 2012). Accordingly, lactate, $\mathrm{pH}$, and other divalent electrolytes in the plasma have been shown to correlate with capture induced stress and mortality in several shark species (e.g. Moyes et al. 2006, Marshall et al. 2012).

In this study we sought to quantify total mortality and post-release survival rates of incidentally captured silky sharks and to identify the point in the purse seine fishing operation when sharks sustain the injuries that lead to mortality. We were able to do this using data collected onboard a commercial tuna purse seine vessel conducting normal fishing practices in the WCPO. To quantitatively assess fishery induced shark mortality, we used lactate concentrates found in the blood in combination with satellite linked pop-up archival transmitting (PAT) tags to validate the fate of released sharks. Other results from the cruise allowed us to investigate the vertical habitat use of silky sharks to identify potential bycatch mitigation strategies, and to assess the accuracy of shark catch rate estimates made by the observer and the vessel officers.

\section{MATERIALS AND METHODS}

\section{Field methods}

Sharks were captured incidentally in purse seine sets for tropical tuna in association with drifting FADs from May through June 2012, during a chartered trip in the western and central Pacific Ocean aboard the US flagged purse seine vessel, M/V Cape Finisterre. This vessel measures $73 \mathrm{~m}$ length overall (LOA) (68 $\mathrm{m}$ waterline) and is rated at 1434 gross registered tonnage (GRT) with a total fish hold capacity of $1149 \mathrm{t}$ of tuna held in 19 brine refrigerated holds. The purse seine net measures $1719 \mathrm{~m}$ long at the corkline and is $\sim 330 \mathrm{~m}$ deep (stretched) (Itano et al. 2012a). Over the course of $41 \mathrm{~d}$ and following normal fishing practices, 31 sets were conducted: 30 around drifting FADs ('FAD associated') and 1 on a free school feeding at the surface ('unassociated' or 'free school') (Fig. 1). To assess post-release survival and to identify the point in the fishing operations when sharks sustain the injuries that result in mortality, we sampled and tagged sharks prior to commencement of fishing (pre-set) and sharks that were landed during each stage of the fishing operations. For a general description of the purse seine fishing procedure see the 


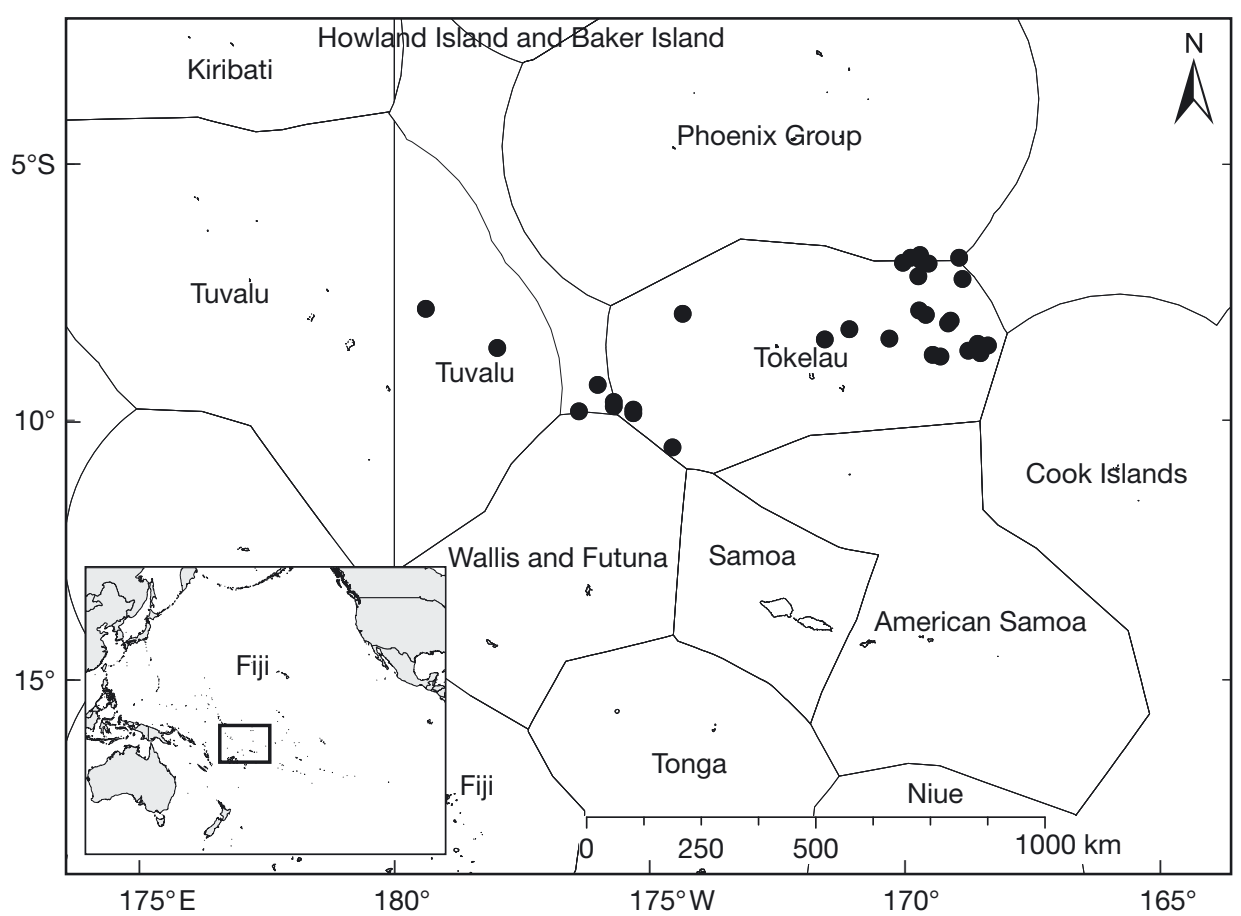

Fig. 1. Purse seine fishing set locations $(\bullet)$. Lines: exclusive economic zones (EEZ) of small island nations in the region
Appendix. The landing stages and control groups identified for this experiment were (1) pre-set: sharks were captured at FADs using dip nets or baited hooks from a small work boat, prior to the onset of fishing, to establish a reference curve of blood biochemistry indicators and to release some sharks that were exposed to a minimal amount of handling. (2) Encircled: these sharks had been encircled by the purse seine net and the net hauled back to at least half net. These sharks were fished out of the net using hook and line, handlines and dipnets during the net 'haul back' while it was still large enough for the sharks to swim freely. They were tagged and sampled onboard the small workboat and then released outside the purse seine net. (3) Entangled: sharks that had become entangled (gilled or meshed) in the purse seine net during 'haul back' and were removed by the fishermen as the net emerged from the water. These sharks got landed early, before sacking up and brailing. (4) First brail: sharks that were brought onto the vessel during the first brail. These sharks would have been on the top of the sack. (5) Later brails: these sharks were landed during any subsequent brails and were confined in the sack for longer periods of time and subjected to the weight of the catch on top of them. Sharks that were recovered during the onboard species composition 'spill' sampling by the observer (Itano et al. 2012a) or recovered from the lower well deck were also considered to have been landed during a later brail.
All sharks were placed upside down in a cradle and ventilated with running seawater while morphometrics were recorded, tags attached and blood withdrawn. Sharks were then released over the side of the vessel and the condition at the time of release was recorded (see Table 1). Release conditions were qualitative and based on a scale from 0 to 4 , where 4 , or 'excellent condition', was recorded for sharks that swam away rapidly without any obvious signs of distress or physical trauma. Sharks released in 'good condition' (3) swam away but appeared slower or disoriented. A 'fair condition' (2) was assigned to sharks whose swimming appeared laborious and/or they exhibited other visible signs of trauma. Sharks in 'poor condition' (1) were able to right themselves and made efforts to swim, while sharks who scored 0, or 'dead', sank upside down.

Three different types of satellite pop-up archive transmitting (PAT) were used to verify post-release survival and to elucidate habitat use and movement behavior: X-Tag (Microwave Telemetry), miniPAT and survival PAT (sPAT; Wildlife Computers). The first 2 tag types continually record and archive detailed behavioral data for user-programmable deployment periods, whereas the latter type of tag (sPAT) is designed specifically to provide only summary behavioral data from which survival or mortality can be inferred over a $30 \mathrm{~d}$ deployment. Programming and data for these tags are proprietary and are provided by Wildlife Computers to the tag 
owner post processing. The X-Tags and mini-PATs were programmed to record temperature, depth, and light level data at specific time intervals and to release after periods of 100 to $360 \mathrm{~d}$. On the scheduled pop-off dates, the tags detach from the tether, float to the surface and transmit the archived data to the Argos satellite system. In the event of a mortality where the shark sinks through the water column, the PATs have an external guillotine device that severs the tag attachment at $\sim 1680 \mathrm{~m}$, before the tag reaches crushing depths. Depth records that went to $1680 \mathrm{~m}$ indicated the shark had died and was sinking. The sPATs transmit the daily maximum and minimum depth and temperature experienced by the shark during deployment. They are programmed to identify the fate of the tag, and thus the shark, by one of 3 designations: (1) Floater: the tag begins to transmit because it was shed by the shark (e.g. due to attachment failure). (2) Sinker: the shark dies and sinks to $1680 \mathrm{~m}$ or dies and remains on the ocean floor at a constant depth. (3) Survivor: the sPAT completes the deployment, the tag initiates a release at $30 \mathrm{~d}$. All sharks that were released alive were also tagged with conventional ID tags (wire through metal dart tag; Hallprint).

Blood sampling consisted of a small volume of blood $(3 \mathrm{ml})$ taken from the caudal vein into heparinized syringes and placed on ice until analysis. Blood chemistry analysis was conducted onboard the vessel immediately after the conclusion of the haul (10 to 120 min post blood withdrawal). To quantify concentrations of lactate, the CG $4+$ cartridge was used with the I-STAT portable automated blood chemistry analyzer (Abbott Laboratories) (Cooke et al. 2008, Gallagher et al. 2010).

\section{Data analysis}

Post-release survival

Survival and mortality events for PAT tagged sharks were interpreted using the transmitted depth records from the tags. In this study, sharks that survived $\geq 10 \mathrm{~d}$ were considered to have survived the fishing interaction. Sharks (tags) that sank to the critical threshold depth $(1680 \mathrm{~m})$ within that time period were considered mortalities. Tags that were shed (Floaters) from sharks that had also been blood sampled within the $10 \mathrm{~d}$ period were not used in the postrelease survival analysis because the reasons the tag detached could not be determined $(n=1)$. Wilcoxon rank sum tests were used to determine which blood parameters differed significantly between survivors and moribund sharks (determined from sharks that were both blood sampled and satellite tagged; see Table 2). Logistic regression models and maximum likelihood estimation was used to predict the probability of survival for sharks that had blood drawn but were not satellite tagged (see Fig. 3). The fitted values $(\hat{\pi})$ were then used to predict survival (and mortality) rates by fishing operation stage and release condition for all of the sharks captured during the cruise (see Tables $3 \& 4$ ).

Silky shark catch rate comparisons

Comparisons of the silky shark catch rates recorded by the scientists, the fisheries observer and the purse seine vessel's officers were conducted to elucidate any differences in reported shark interactions (catch) using repeated measures analysis of variance (ANOVA) followed by Tukey's post-hoc multiple comparisons (see Fig. 4). In addition, a linear regression analysis was used to investigate whether or not the weight (tonnage) of the total tuna catch had an effect on the mortality rates of sharks per set. Predicted mortality rates using lactate levels and landing stage (as determined above) were compared to the tuna catch sizes derived from the observer data. All statistical data analysis was performed using the R software package (R Development Core Team 2013).

Habitat use and vertical behavior

The transmitted vertical movement data from the miniPAT satellite tags was analyzed to identify diel vertical shifts in depth or temperature preferences. Analysis and illustration of the tag data was completed using IgorPro 6.3 (WaveMetrics).

\section{RESULTS}

A total of 295 juvenile silky sharks with lengthbased age estimates of 0 to $4(115.2 \pm 17.5 \mathrm{~cm}$ mean total length) were captured during 31 fishing sets conducted over $45 \mathrm{~d}$ at sea (Fig. 1). Age at length information was derived from Joung et al. (2008). Landing stage and release condition information was recorded for each shark (Table 1). Twenty-eight silky sharks landed during different stages of the fishing operation were tagged with satellite tags (15 sPATs, 
Table 1. Number and condition (scale 0 to 4 ) of silky sharks Carcharhinus falciformis released during each fishing stage

\begin{tabular}{|lcccccccc|}
\hline & \multicolumn{8}{c|}{ Release condition } \\
\cline { 2 - 8 } & $\begin{array}{l}\text { Excellent Good } \\
(4)\end{array}$ & $\begin{array}{c}\text { Fair } \\
(3)\end{array}$ & $\begin{array}{c}\text { Poor } \\
(2)\end{array}$ & $\begin{array}{c}\text { Dead } \\
(1)\end{array}$ & $\begin{array}{c}\text { Un- } \\
\text { (0) }\end{array}$ & known & \\
\hline Pre-set & 9 & 1 & 0 & 0 & 0 & 0 & 10 \\
Encircled & 6 & 0 & 1 & 0 & 0 & 0 & 7 \\
Tangled & 24 & 5 & 3 & 1 & 3 & 1 & 37 \\
1st brail & 0 & 1 & 5 & 7 & 14 & 3 & 30 \\
Brail & 0 & 9 & 12 & 26 & 148 & 16 & 211 \\
Total & 39 & 16 & 21 & 34 & 165 & 20 & 295 \\
\hline
\end{tabular}

11 miniPATS and $2 \mathrm{X}$-Tags; Table 2). The $2 \mathrm{X}$-Tags did not report, whereas all the sPATs and miniPATs transmitted deployment records. Blood samples were collected from 87 sharks, 17 of which were also satellite tagged and released to establish biochemical stress indices that correlate with mortality for this species. To date none of the sharks tagged with conventional ID tags $(n=132)$ have been recaptured and/or reported.

\section{Post-release survival}

Shark morphometrics, stage of capture, release condition, lactate concentrations, PAT fate and tag deployment periods for satellite tagged sharks are given in Table 2. Survival was determined using the depth records from satellite tagged sharks. Significant differences in lactate concentrations were found (Wilcoxon rank sum, $\mathrm{n}=14, \mathrm{p}<0.01$ ) between satellite tagged sharks that survived the fishing encounter (tag deployment $\geq 10 \mathrm{~d}, \mathrm{n}=9$ ) and those that died post release $(0-9 d, n=5)$. There were 4 delayed mortalities of satellite tagged sharks at 15, 25, 30 and $129 \mathrm{~d}$ (Table 2). These mortalities cannot be directly attributed to the fishing encounter and so were considered survivors. Two of the tags on sharks that had also been blood sampled did not report and 1 was shed after only $5 \mathrm{~d}$ so these were not used in the analysis. Logistic regression analysis showed that lactate concentrations are a good predictor of survival for sharks that had been blood sampled but were not satellite tagged (lactate: logit survival

Table 2. Satellite tagged shark morphometric, blood chemistry and tag deployment data for silky shark Carcharhinus falciformis. TL: total length. NA: not available. Release condition: see Table 1

\begin{tabular}{|c|c|c|c|c|c|c|c|c|}
\hline Tag type & ID & Sex & $\mathrm{TL}(\mathrm{cm})$ & $\begin{array}{l}\text { Fishing } \\
\text { stage }\end{array}$ & $\begin{array}{l}\text { Lactate } \\
\left(\mathrm{mmol} \mathrm{l}^{-1}\right)\end{array}$ & $\begin{array}{c}\text { Release } \\
\text { condition }\end{array}$ & PAT fate & $\begin{array}{l}\text { Deploy- } \\
\text { ment (d) }\end{array}$ \\
\hline miniPAT & 54245 & M & 105 & Pre-set & NA & 4 & Floater & 26 \\
\hline miniPAT & 54246 & M & 104 & Encircled & NA & 2 & Floater & 34 \\
\hline miniPAT & 54247 & M & 104 & Pre-set & NA & 4 & Floater & 3 \\
\hline miniPAT & 54305 & $\mathrm{M}$ & 127 & Encircled & NA & 4 & Floater & 6 \\
\hline miniPAT & 54249 & $\mathrm{M}$ & 93 & Pre-set & NA & 4 & Floater & 15 \\
\hline miniPAT & 54267 & $\mathrm{~F}$ & 116 & Entangled & 1.19 & 4 & Floater & 5 \\
\hline miniPAT & 54270 & M & 145 & Entangled & 2.37 & 4 & Sinker & 129 \\
\hline miniPAT & 54274 & $\mathrm{M}$ & 144 & Entangled & NA & 4 & Floater & 32 \\
\hline miniPAT & 62937 & M & 122.5 & Entangled & 5.3 & 4 & Floater & 10 \\
\hline miniPAT & 62936 & M & 133 & Entangled & 2.19 & 4 & Survivor & 100 \\
\hline miniPAT & 62941 & $\mathrm{~F}$ & 136 & Entangled & 12.07 & 3 & Sinker & 0 \\
\hline sPAT & 117916 & M & 123 & Entangled & 14.47 & 4 & Sinker & 25 \\
\hline sPAT & 117917 & $\mathrm{~F}$ & 128 & 1st brail & 17.51 & 0 & Sinker & 0 \\
\hline sPAT & 117918 & M & 107 & Entangled & NA & 1 & Sinker & 0 \\
\hline sPAT & 117919 & $\mathrm{U}$ & 110 & Entangled & 2.13 & 4 & Survivor & 30 \\
\hline sPAT & 117920 & $\mathrm{~F}$ & 128 & 1st brail & NA & 2 & Sinker & 0 \\
\hline sPAT & 117921 & M & 116 & Entangled & 2.88 & 4 & Survivor & 30 \\
\hline sPAT & 117922 & M & 137 & Brail & 13 & 2 & Survivor & 30 \\
\hline sPAT & 117923 & M & 125 & Entangled & 1.99 & 3 & Sinker & 15 \\
\hline sPAT & 117924 & $\mathrm{M}$ & 105 & 1st brail & NA & 1 & Sinker & 0 \\
\hline SPAT & 117925 & $\mathrm{~F}$ & 104 & Encircled & NA & 4 & Survivor & 30 \\
\hline sPAT & 117926 & $\mathrm{~F}$ & 119 & Pre-set & 1.87 & 4 & Sinker & 30 \\
\hline sPAT & 117927 & M & 111 & Brail & 14.91 & 0 & Sinker & 0 \\
\hline sPAT & 117928 & $\mathrm{~F}$ & 111 & 1st brail & 15 & 0 & Sinker & 0 \\
\hline sPAT & 117929 & M & 93 & Entangled & NA & 4 & Floater & 23 \\
\hline SPAT & 117930 & $\mathrm{M}$ & 107 & Brail & 13.79 & 1 & Sinker & 0 \\
\hline X-Tag & 19899 & $\mathrm{~F}$ & 128 & Entangled & 14.61 & 4 & NA & - \\
\hline $\mathrm{X}$-Tag & 52210 & M & 128 & Entangled & 14.08 & 4 & NA & - \\
\hline
\end{tabular}


$\sim-0.891 \times\left[\right.$ Lactate $\left.\mathrm{mmol} \mathrm{l}^{-1}\right]+10.5757, \mathrm{p}<0.001, \mathrm{r}^{2}=$ $0.76)$.

To obtain the probability of survival $(\hat{\pi})$ (for sharks that were not satellite tagged) the maximum likelihood estimates $\left(b_{0}=10.5757, b_{1}=-0.891\right)$ for the lactate survival curve were substituted into the response function:

$$
\hat{\pi}=\frac{\exp \left(b_{0}+b_{1}{ }^{*} X\right)}{1+\exp \left(b_{0}+b_{1}{ }^{*} X\right)}
$$

Survival was set at $\hat{\pi}>0.5$, and the lactate concentration at $\hat{\pi}=0.5$ was found to be equal to $11.3 \mathrm{mmol}$ $\mathrm{l}^{-1}$ (Fig. 2). Thus, all sharks with a lactate value of $11.3 \mathrm{mmol}^{-1}$ and higher were considered moribund. Using these criteria, mean survival probabilities were then estimated for each landing stage and release condition for the sharks whose blood was sampled. These values were then applied to the rest of the data set (sharks that were not blood sampled) to extrapolate survival rates by landing stage and release condition for all of the sharks encountered during this cruise $(\mathrm{n}=295$; see Tables $3 \& 4)$.

Sharks caught at the FADs during pre-set fishing excursions and those sampled after having been encircled by the purse seine net showed $100 \%$ postrelease survival, indicating there was no measureable effect from the tagging and blood sampling procedures or from the encirclement process. We found higher survival rates $(68.7 \%)$ for sharks that had become entangled in the net than for sharks that

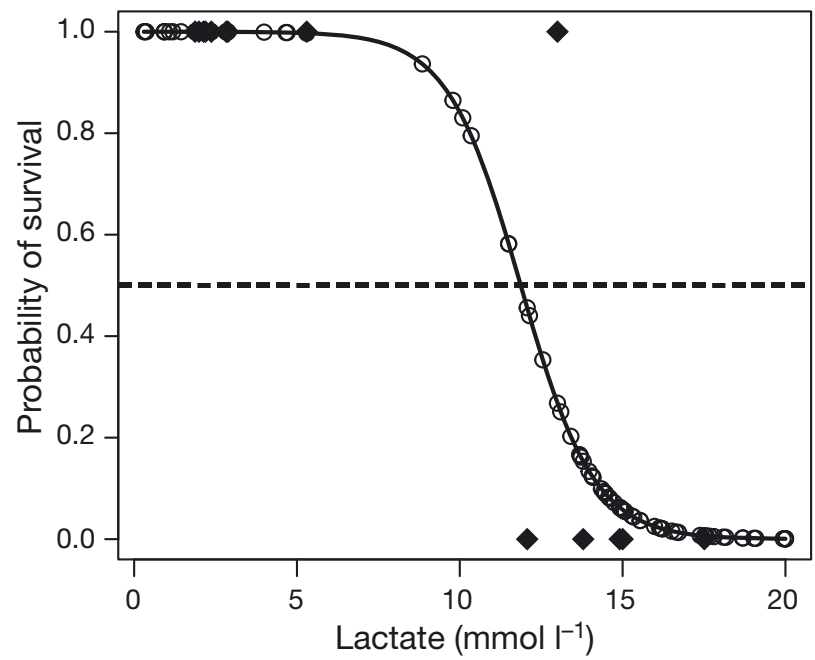

Fig. 2. Survival probability curve using lactate $\mathrm{mmol}^{-1}$ concentrations for satellite tagged silky sharks $(\diamond)$ that either survived the fishing interaction (1) or died post release (0). Fitted probabilities (O): sharks that had blood drawn but were not satellite tagged. Probability of survival (dashed line $=0.5$ ): sharks predicted to have survived (above line) the fishing event, or suffered mortality (below line) came up in the first brail $(16.7 \%)$. Total survival rates were lowest $(6.7 \%)$ for sharks loaded during any of the later brails. This culminated in an overall postrelease survival rate of $15.8 \%$ for sharks landed during typical fishery operations (i.e. pre-set and encircled sharks excluded) which corresponds to a total mortality rate of $84.2 \%$ (Table 3 ) for purse seine captured silky sharks. We also found that observing and documenting the landing stage and/or release condition of each shark can be a reliable predictor of post-release fate (Table 4).

\section{Silky shark catch comparisons}

The shark catch data recorded by the observer, the vessel officers and the scientists were compared for sets 14 to 31 (Fig. 3). Sets 1 to 13 were omitted from this analysis because the observer and scientists were initially comparing shark catch data and so they were not independent estimates. A one-way ANOVA revealed significant differences in recorded shark catch between the scientists, the observer and the vessel's logbook $(F=9.592, \mathrm{p}=0.0005)$. Tukey-

Table 3. Predicted survival by stage of fishing operation. Number of silky sharks Carcharhinus falciformis landed (n) and predicted survival for each stage. Parentheses: total survival for regular fishing operations (pre-set fishing and encirclement stages removed). Total mortality rate for juvenile silky sharks landed during typical fishing stages $=84.17 \%$

\begin{tabular}{|lccc|}
\hline Landing stage & $\mathrm{n}$ & $\begin{array}{c}\text { Predicted } \\
\text { survival (\%) }\end{array}$ & $\begin{array}{c}\text { No. of } \\
\text { survivors }\end{array}$ \\
\hline Pre-set & 10 & 100 & 10 \\
Encircled & 7 & 100 & 7 \\
Tangled & 37 & 68.4 & 25 \\
1st brail & 30 & 16.7 & 5 \\
Brail & 211 & 6.67 & 14 \\
Total & $295(278)$ & $20.68(15.83)$ & $61(44)$ \\
\hline
\end{tabular}

Table 4. Predicted survival rates by release condition. Some silky sharks were released without a release condition recorded

\begin{tabular}{|lccc|}
\hline $\begin{array}{l}\text { Release } \\
\text { condition }\end{array}$ & $\mathrm{n}$ & $\begin{array}{c}\text { Predicted } \\
\text { survival }(\%)\end{array}$ & $\begin{array}{c}\text { No. predicted } \\
\text { survivors }\end{array}$ \\
\hline Excellent & 39 & 91.67 & 35.75 \\
Good & 16 & 11.49 & 1.84 \\
Fair & 21 & 6.897 & 1.45 \\
Poor & 34 & 0 & 0 \\
Dead & 165 & 2.94 & 4.85 \\
\hline
\end{tabular}




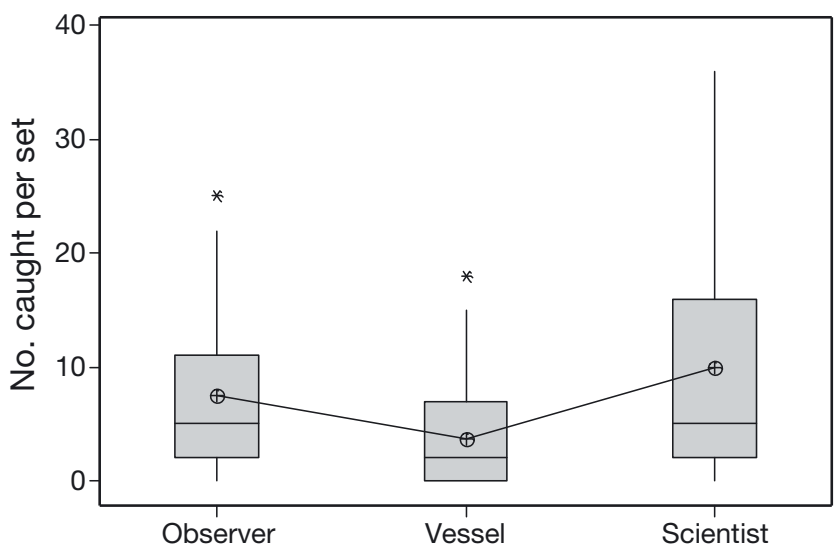

Fig. 3. Silky shark Carcharhinus falciformis catch rate comparisons between the fishery observer, vessel log and the scientists. Bottom and top of boxes: first (25\%) and third (75\%) quartiles; horizontal lines: median; whiskers: upper and lower limits of the data; asterisks: outliers; crosses connected by the line: means of total shark catch recorded per set

Kramer multiple comparisons show both the observer and the vessel reported significantly fewer sharks than the scientists (observer vs. scientists: -4.722 , $\mathrm{p}<0.05$; vessel vs. scientists: $-7.611, \mathrm{p}<0.001$ ). While the observer consistently recorded more sharks per set than the vessel, the difference was not significant $(2.889, \mathrm{p}>0.05)$.

We also investigated the possibility that the mortality rates of silky sharks captured in the purse seine were dependent on the size (tonnage) of the total tuna catch. We used linear regression analysis to describe the relationship between catch sizes (taken from the observer data) and predicted mortality rates of silky sharks caught during each set. The model showed that catch size (t) does not explain a significant component of the shark mortality rates (mortality rate $=0.622+0.00233$ total catch, $F_{1,26}=2.39, \mathrm{p}=$ $0.134, r^{2}=0.084$ ).

\section{Habitat use and vertical behavior}

The satellite data acquired from the 26 PATs that transmitted resulted in $575 \mathrm{~d}$ of data. Our analysis of the tag data revealed diel vertical patterns within the upper $100 \mathrm{~m}$ of the water column with irregular and rare deeper dives beyond the thermocline (Figs. 4 \& 5). Preferred daytime depths are shallower $(0-40 \mathrm{~m})$ than nighttime depths $(60-80 \mathrm{~m})$ with increased dive frequencies beyond $100 \mathrm{~m}$ at night (Fig. 4). All sharks spent the greatest proportion of their time within the upper mixed layer, which extends to about $110 \mathrm{~m}$ in this region. Tag data also showed silky sharks occupying a very narrow temperature range of $29.0^{\circ} \pm$ $0.58^{\circ} \mathrm{C}( \pm \mathrm{SD})$.

\section{DISCUSSION}

Silky sharks are among the oceans most heavily exploited elasmobranch species. They are captured as bycatch in several commercial fisheries worldwide but are also targeted for their fins and meat in several regions. The most recent stock assessment of silky

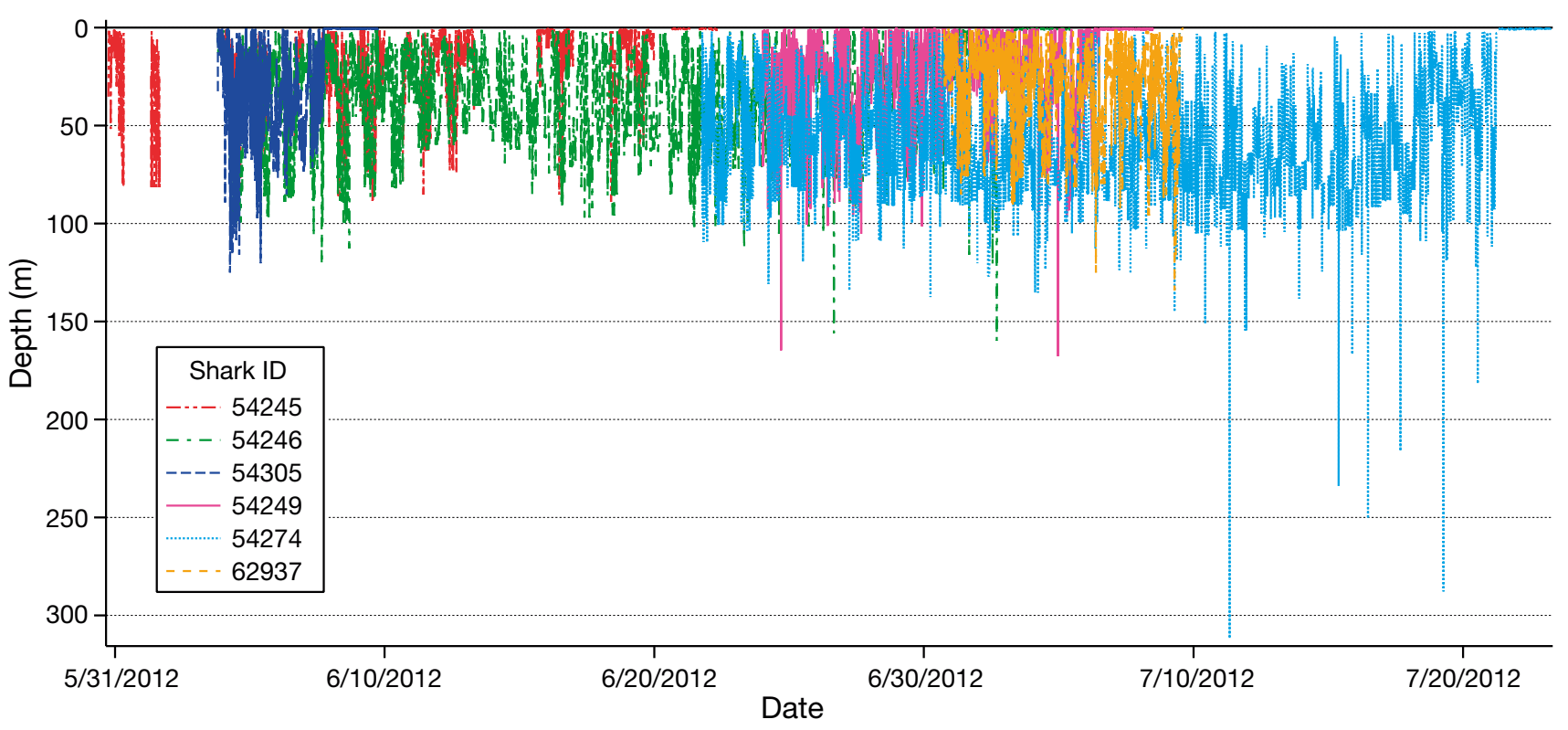

Fig. 4. Vertical habitat use of 6 silky sharks tagged with miniPATs. Date: m/dd/yyyy 

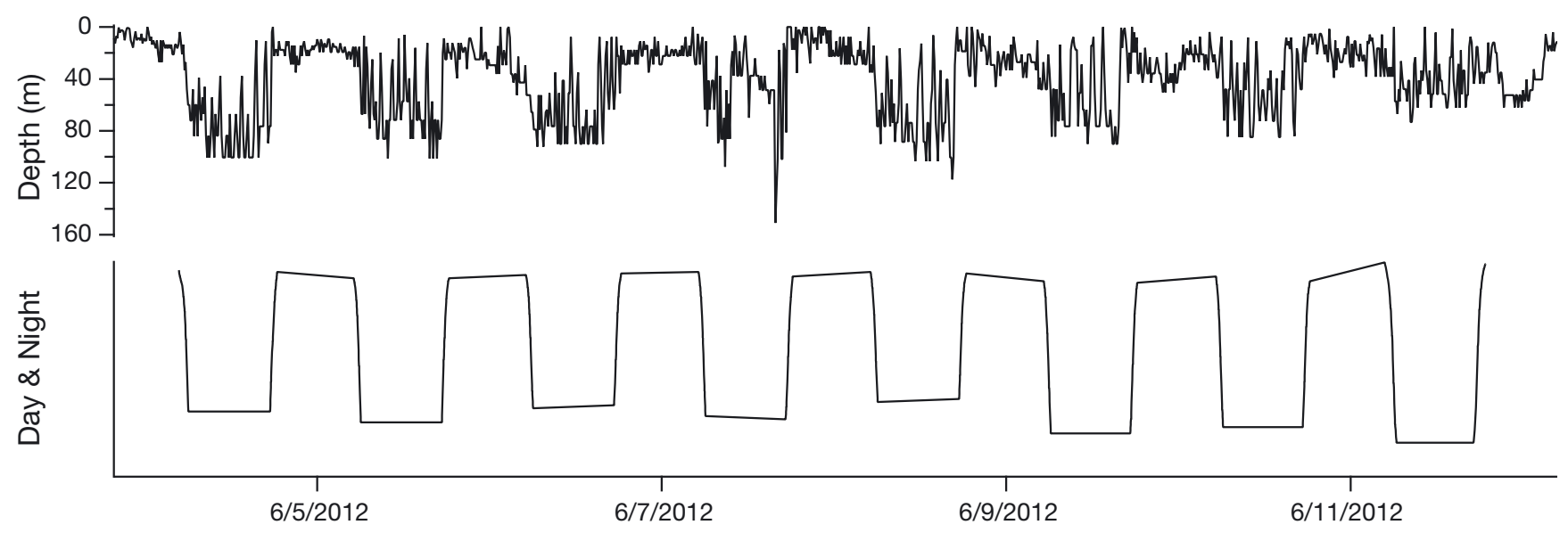

Fig. 5. Diel vertical movement behavior of silky shark 54246. Top row; depth time series of 1 silky shark over a period of $7-24 \mathrm{~h}$ day/night cycles. Bottom row: light levels to infer dawn, day time (upper lines), dusk and night times (lower lines). Dates are $\mathrm{m} / \mathrm{dd}$ /yyyy

sharks for the Western Central Pacific Fisheries Commission (WCPFC) concluded that overfishing is occurring and that the population is in a state of decline primarily due to large increases in fishing mortality (Rice \& Harley 2013). Longline fishing was attributed with the greatest impact on the silky shark population due to the relative level of fishing effort compared to that of the purse seine fishery, but bycatch from sets on drifting FADs was found to contribute a significant proportion of the silky shark fishing mortality. Many of the studies dealing with shark bycatch and discard mortality have been focused solely on the effects of capture in longline fisheries (Moyes et al. 2006, Hight et al. 2007, Marshall et al. 2012) while purse seine fisheries have received little attention (Poisson et al. 2014). In this study we reveal the post-release survival rates of sharks tagged and released at different purse seine fishing stages. By relating this to blood biochemistry, we were able to extrapolate the survival rates observed in the tagged sharks by landing stage and release condition, and thereby obtain overall estimates of total mortality, as well as identifying the point in the fishing interaction when sharks sustain the injuries that lead to mortality. This, in combination with the vertical habitat use data from the satellite tags, gave us some insight into where efforts to mitigate shark bycatch in this fishery should be focused.

\section{Post-release survival}

Several studies have demonstrated that sharks incidentally captured in fisheries and subsequently discarded at sea suffer high rates of post-release mortality from the physical trauma and physiological stress experienced during capture (eg Hight et al. 2007,
Campana et al. 2009, Mandelman \& Skomal 2009, Frick et al. 2012, Poisson et al. 2014). Many of these studies have also revealed several blood chemistry parameters that correlate to the post-release fate of pelagic sharks. The nature and extent of these blood chemistry disturbances are species specific and found to correspond to the activity level (swimming speeds) and ecology (pelagic, coastal, demersal) of each species (Skomal 2007, Marshall et al. 2012). Yet in many commercial fishery and experimental scenarios lactate concentrations were affected across species (e.g. Mandelman \& Skomal 2009, Hyatt et al. 2012). In this study lactate concentrations were significantly different between survivors and moribund sharks, and found to be a good predictor of survival. Increased lactate loads lead to metabolic acidosis when lactate and hydrogen ions are formed in the muscle tissue during anaerobic respiration (Cliff \& Thurman 1984). The stress of confinement in a purse seine likely results in a cascade of physiological perturbations from the point in the haul back, where the shark begins to struggle against the net, to the point where they have been confined in the sack and gas exchange is limited. Accordingly, moribund sharks showed high lactate concentrations whereas sharks that survived the capture event had lower lactate concentrations $\left(<11 \mathrm{mmol} \mathrm{l}^{-1}\right)$.

Sharks that were captured, while still free-swimming, during the pre-set sampling and from inside the net (encircled sharks) had 100\% post-release survival rates. This suggests that the effects of tagging and the simple act of surrounding the sharks by the purse seine net does not affect survival. Sharks that had become entangled in the net and were released during the net haul had relatively high survival rates $(68 \%)$ and probably reflected the amount 
of time between becoming entangled and when that portion of the net was retrieved. Regardless, a higher survival probability for entangled sharks highlights the importance of good handling practices for the safe removal and release of sharks caught in the nets (Poisson et al. 2013, 2014). A study on the postrelease survival of silky sharks captured in a purse seine conducted in the Indian Ocean also found higher survival rates in sharks landed via entanglement $(82 \%$, Poisson et al. 2014). Fewer sharks were landed via entanglement in the Indian Ocean than in this study, so the higher survival rates for entanglement there may reflect differences in fishing techniques (e.g. set times or net specs) between studies.

We anticipated that sharks that were landed during the first brail would also have good survival rates, because these sharks would have been at the surface, not exposed to the weight of the catch, and released after a much shorter period of time than sharks that were deeper in the sack and landed in later brails. However survival rate of first brail sharks was low $(17 \%)$ and not much better than for those landed in subsequent brails $(7 \%)$. Direct visual observations carried out using SCUBA gear and documented with HD video and digital still photography (see Muir et al. 2012) confirmed that silky sharks appeared exhausted from struggling against the net during the final stages of net hauling. At that point they would slide down the edge of the net and become buried beneath the tuna at the bottom before the fishers even began 'sacking up' the net (Muir et al. 2012). Higher lactate concentrations in sharks landed during the later brails corroborate our visual observations of the sharks struggle against the net during the end of the haul. This behavior may explain why only a small proportion of sharks were found in first brails and why the size of the haul (weight of the total tuna catch) did not have a significant effect on the mortality rates: crushing under the weight of the tuna catch is not the cause of mortality. The inability to ram ventilate and the stress of confinement probably leads to mortality before they are injured by being crushed by the weight of the tuna catch above them. Thus, once the shark has been confined in the sack portion of the net, its chances of survival have been severely compromised.

Overall, total mortality for sharks captured and loaded via typical fishing operations (pre-set and encircled stages excluded) was $84 \%$. Poisson et al. (2014) also found high total mortality rates (81\%) of silky sharks captured in purse seines. This indicates that only a small proportion of sharks captured and subsequently discarded in purse seine fisheries are going to survive the interaction. These results emphasize the relative ineffectiveness of 'no retention' policies as a management tool for purse seine fisheries. Releasing sharks from the deck after they have been loaded to the vessel through brailing will not reduce fishing mortality in this fishery. Our results do highlight the importance of total avoidance or early release through mechanisms such as a release panel (Itano et al. 2012b) or other methods while the sharks are still free swimming. Obviously, avoiding the encirclement of sharks altogether is the best means of reducing the impact this fishery has on juvenile silky sharks, and points to the importance of technical solutions to this problem in tandem with other management measures.

\section{Catch comparisons}

Comparison of the number of captured sharks observed by the scientific party and those reported by the vessel and fishery observer revealed that there are significant recording discrepancies regarding the number of sharks impacted by this fishery. We found catch rates were significantly underestimated by both the observer and the vessel logbook. There did not appear to be any deliberate underreporting, and differences are most likely due to the nature of the fishing operation; brails are loaded quickly $\left(0.5 \mathrm{t} \mathrm{min}^{-1}\right.$, pers. obs.), vessel operators are not paying attention to undesirable species, and observers are occupied conducting the various catch sampling and estimation duties in addition to documenting all bycatch. The use of a sorting "hopper" and having the operator close the trap door to slow down the descent of the catch in to the wells greatly enhanced our ability to see and then pull sharks for sampling before they went down the chute into the holds. Regardless of the causes, the differences in recorded shark catch rates that we observed should be given appropriate attention when conducting stock assessments based on observer and logbook catch data. It is also worth noting that due to the variety of vessels in the tropical tuna purse seine fishery, loading and hold styles vary dramatically, and this should be taken into account when considering these estimates.

\section{Habitat use and vertical behavior}

Understanding silky shark movement behavior, habitat use and FAD residence times is important when conceptualizing bycatch mitigation techniques. 
There is a general lack of information on the associative behavior of juvenile silky sharks at FADs, but in the WCPO purse seine fishery, twice as many silky sharks are captured in FAD-associated sets than unassociated sets (Clarke et al. 2011), and aggregations of juvenile silky sharks at FADs have been documented in several studies (Lennert-Cody \& Hall 2000, Watson et al. 2008, Filmalter et al. 2011). A study of 10 juvenile silky sharks acoustically tagged in the Indian Ocean at drifting FADs (Filmalter et al. 2011) found continuous residence times (CRT: periods of absence not exceeding $24 \mathrm{~h}$ ) of 0.42 to $10.7 \mathrm{~d}$. The movement data we acquired using electronic tags during this cruise gave us some insight into the vertical and horizontal behavior of juvenile silky sharks. The most pertinent result for this fishery was that juvenile silky sharks remain in the upper $100 \mathrm{~m}$ of the water column whether they are in association with a FAD or not. Diel shifts were observed, where sharks are deeper at night $(\sim 70 \mathrm{~m})$ and shallower during the day ( 0 to $40 \mathrm{~m}$ ); their vertical structure is within the upper mixed layer which extends to $110 \mathrm{~m}$ in this region. Purse seine net depths measured using temperature-depth recorders placed at 3 different locations on the net during the cruise gave net depths ranging from $142 \mathrm{~m}$ at the shallower edges to over $200 \mathrm{~m}$ in the center (Itano et al. 2012a). Thus, the depth preferences of silky sharks keep them within the vertical range of the purse seine nets at all times of the day. Essentially, juvenile silky sharks do not exhibit behaviors that would allow them to avoid capture under normal fishing conditions and practices.

\section{CONCLUSIONS}

Our analysis revealed high total mortality rates of $84.2 \%$ to juvenile silky sharks under current purse seine fishing practices. We found that post-release survival was dependent on which stage in the fishing process the shark was loaded onto the vessel. Our results indicate that early release (entangled sharks, or through a release panel built into the net) could significantly reduce the impact FAD-based purse seine fishing has on silky shark populations. This is of particular management interest because all of the sharks encountered during this cruise were juveniles, and demographic studies have shown that silky shark population growth is highly dependent on juvenile survival (ages 0-5; Roman-Verdesoto 2014). If the current level of purse seine fishing effort on FADs is not mitigated, silky shark populations could be driven beyond the point of recovery.
We documented significant differences in the shark catch estimates made by the vessel's crew and when compared to catch estimates recorded by the observer and the scientific party. We suggest that these discrepancies be factored into future stock assessments of silky shark populations. These assessments would also be strengthened by additional data fields recorded by observers. If shark landing stage and release condition information were also documented, better estimates of fishing mortality could be used in future population models.

This study found that silky shark behavior in the net at the end of the net haul in combination with the physiology of this species is what contributes to the high overall mortality rates that we observed. Essentially, a large proportion of the sharks captured in a purse seine are not going to survive the interaction. In the $\mathrm{WCPO}$, the longline fishery has the largest effect on the overall silky shark fishing mortality due to the level of fishing effort alone. Thus, post-release survival studies are necessary for commercial longline fisheries. On the whole, more complete, speciesspecific information of fishing mortality in these and other fisheries is necessary before useful stock assessment and population level management can result.

Acknowledgements. We thank the International Seafood Sustainability Foundation for conceiving and funding the Bycatch Project. Thanks to Susan Jackson and Victor Restrepo for supporting our research objectives and getting us on a fishing vessel. We thank Tri Marine Group for supporting the Bycatch Project initiative and for providing their flagship vessel as a research platform. We are indebted to the captain and crew of the M/V Cape Finisterre. We acknowledge the contributions from the Secretariat of the Pacific Community, National Marine Fisheries Service Pacific Island Fisheries Science Center, Western Pacific Fishery Management Council, WCPFC and FFA. We thank Bruno Leroy and Feral Lasi of the SPC and Elton Clodamur of the Marshall Islands Marine Resources Agency for their help at sea. We also acknowledge Drs. Andrew Taylor, Anna Neuheimer and Andre Seale at the University of Hawaii for assistance with data analysis.

\section{LITERATURE CITED}

Amandè MJ, Chassot E, Chavance P, Pianet, R (2008) Silky shark Carcharhinus falciformis bycatch in the French tuna purse-seine fishery of the Indian Ocean. IOTC2008-WPEB-16, Indian Ocean Tuna Comm Proc

Amandè MJ, Ariz J, Chassot E, Delgado de Molina A and others (2010) Bycatch of the European purse seine tuna shery in the Atlantic Ocean for the 2003-2007 period. Aquat Living Resour 23:353-362

Beerkircher L, Shivji M, Cortés E (2003) A Monte Carlo demographic analysis of the silky shark Carcharhinus 
falciformis: implications of gear selectivity. Fish Bull 101: 168-174

Campana SE, Joyce W, Manning MJ (2009) Bycatch and discard mortality in commercially caught blue sharks Prionace glauca assessed using archival satellite pop-up tags. Mar Ecol Prog Ser 387:241-253

Clarke S (2011) A status snapshot of key shark species in the Western and Central Pacific and Potential Management Options. WCPF-SC7-2011, EB-WP-04, Pohnpei

Clarke S, Harley S, Hoyle S, Rice J (2011) An indicatorbased analysis of key shark species based on data held by SPC-OFP. WCPF-SC7-2011, EB-WP-01, Pohnpei

Cliff G, Thurman GD (1984) Pathological and physiological effects of stress during capture and transport in the juvenile dusky shark Carcharhinus obscurus. Comp Biochem Phys A 78:167-173

Cooke SJ, Suski CD, Danylchuk SE, Danylchuk AJ and others (2008) Effects of different capture techniques on the physiological condition of bonefish Albula vulpes evaluated using field diagnostic tools. J Fish Biol 73: 1351-1375

Cortes E (2002) Incorporating uncertainty into demographic modeling: application to shark populations and their conservation. Conserv Biol 16(4):1048-1062

Dagorn L, Holland KN, Restrepo V, Moreno G (2013) Is it good or bad to fish with FADs? What are the real impacts of the use of drifting FADs on pelagic marine ecosystems? Fish Fish 14(3):391-415

Filmalter JD, Dagorn L, Cowley PD, Taquet M (2011) First descriptions of the behavior of silky sharks, Carcharhinus falciformis, around drifting fish aggregating devices in the Indian Ocean. Bull Mar Sci 87(3):325-337

Fonteneau A, Pallares P, Pianet R (2000) A worldwide review of purse seine fisheries on FADs. Pêche thonière et dispositifs de concentration de poissons, Caribbean-Martinique, 15-19 Oct 1999, available at: http://archimer. ifremer.fr/doc/00042/15278/ (accessed October 2013)

Frick LH, Walker TI, Reina RD (2012) Immediate and delayed effects of gill-net capture on acid-base balance and intramuscular lactate concentration of gummy sharks, Mustelus antarcticus. Comp Biochem Phys A 162(2):88-93

Gallagher AJ, Frick LH, Bushnell PG, Brill RW, Mandelman JW (2010) Blood gas, oxygen saturation, $\mathrm{pH}$, and lactate values in elasmobranch blood measured with a commercially available portable clinical analyzer and standard laboratory instruments. J Aquat Anim Health 22(4): 229-234

Gilman E, Lundin C (2008) Principles and methods to minimize bycatch of sensitive species groups in marine capture fisheries: lessons from commercial tuna fisheries. In: Grafton Q, Hillborn R, Squires D, Tait M, Williams M (eds) Handbook of marine fisheries conservation and management. Oxford University Press, Oxford

Hight BV, Holts D, Graham JB, Kennedy BP and others (2007) Plasma catecholamine levels as indicators of the post-release survivorship of juvenile pelagic sharks caught on experimental drift longlines in the Southern California Bight. Mar Freshwater Res 58:145-151

Itano D, Muir J, Hutchinson M, Leroy B (2012a) Overview of the ISSF bycatch mitigation research cruise in the WCPO. WCPFC-SC8 EB-WP-11, Busan

Itano D, Muir J, Hutchinson M, Leroy B (2012b) Development and testing of a release panel for sharks and nontarget finfish in purse seine gear. WCPFC-SC8 EB-WP-

\section{4, Busan}

Joung SJ, Chen CT, Lee HH, Liu KM (2008) Age, growth, and reproduction of silky sharks Carcharhinus falciformis in northeastern Taiwan waters. Fish Res 90:78-85

Lawson T (2011) Estimation of catch rates and catches of key shark species in tuna fisheries of the western and central Pacific Ocean using observer data. WCPFC-SC7 EBIP-02, Pohnpei

Lennert-Cody CE, Hall MA (2000) The development of the purse seine fishery on drifting fish aggregating devices in the eastern Pacific Ocean. In: Le Gall JY, Cayré P, Taquet $M$ (eds) Pêche thonière et dispositifs de concentration de poissons. IFREMER Actes Colloq, CaraibeMartinique, p 87-107

Mandelman JW, Skomal GB (2009) Differential sensitivity to capture stress assessed by blood acid-base status in five carcharhinid sharks. J Comp Physiol B 179(3):267-277

Marshall H, Field L, Afiadata A, Sepulveda C, Skomal G, Bernal D (2012) Hematological indicators of stress in longline-captured sharks. J Comp Biochem Phys A 162(2):121-129

Moyes CD, Fragoso N, Musyl MK, Brill RW (2006) Predicting post release survival in large pelagic fish. Trans Am Fish Soc 135(5):1389-1397

Muir J, Itano D, Hutchinson M, Leroy B, Holland K (2012) Behavior of target and non-target species on drifting FADs and when encircled by purse seine gear. WCPFCSC8 EB-WP-13, Busan

Poisson F, Séret B, Vernet al. Goujon M, Dagorn L (2013) Collaborative research: development of a manual on elasmobranch handling and release best practices in tropical tuna purse-seine fisheries. Mar Policy 44: 312-320,

Poisson F, Filmalter JD, Vernet A-L, Dagorn L (2014) Mortality rate of silky sharks (Carcharhinus falciformis) caught in the tropical tuna purse seine fishery in the Indian Ocean. Can J Fish Aquat Sci 71(6):795-798

R Development Core Team (2013) R: a language and environment for statistical computing. R Foundation for Statistical Computing, Vienna

Renshaw G, Kutek AK, Grant GD, Anoopkumar-Dukie S (2012) Forecasting elasmobranch survival following exposure to severe stressors. Comp Biochem Phys A 162(2):101-112

Rice J, Harley S (2013) Updated stock assessment of silky sharks in the western and central Pacific Ocean. WCPFC-SC9 SA-WP-03, Pohnpei

Román-Verdesoto MH (2014) Potential effects of spatial closures on the demography of silky shark Carcharhinus falciformis in the eastern Pacific Ocean. MSc thesis, Centro de Investigación Científica y de Educación Superior de Ensenada (CICESE), Baja California

Román-Verdesoto MH, Orozco-Zoller M (2005) Bycatches of sharks in the tuna purse-seine fishery of the eastern Pacific Ocean reported by observers of the Inter-American Tropical Tuna Commission, 1993-2004. Data Rep 11, IATTC, La Jolla, CA

Skomal GB (2007) Evaluating the physiological and physical consequences of capture on post release survivorship in large pelagic fishes. Fish Manag Ecol 14(2):81-89

Skomal GB, Mandelman JW (2012) The physiological response to anthropogenic stressors in marine elasmobranch fishes: a review with a focus on the secondary response. Comp Biochem Phys A 162(2):146-155 
Watson JT, Essington TE, Lennert Cody CE, Hall MA (2008) Trade offs in the design of fishery closures: management of silky shark bycatch in the eastern Pacific Ocean tuna fishery. Conserv Biol 23(3):626-635

Williams P, Terawasi P (2013) Overview of tuna fisheries in the western and central Pacific Ocean, including economic conditions - 2012. WCPFC-SC9 GN-WP-1, Pohnpei Worm B, Davis B, Kettemer L, Ward-Paige CA and others (2013) Global catches, exploitation rates, and rebuilding options for sharks. Mar Policy 40:194-204

Appendix. Purse seine fishing operation overview

A typical purse seine fishing set begins when the skiff attached to the net at the stern of the purse seiner releases from the vessel and they both drive in opposite directions to surround the school with the net. Surrounding the school takes $9 \mathrm{~min}$ on average. The vessel then begins 'pursing' the net by drawing the chain at the base of the net up to enclose the encircled school within the net (20-25 min). The vessel then begins to 'haul back' the net, restacking it at the stern of the vessel with the use of a large hydraulic block (wheel). Once most of the net has been recovered and stacked, the crew begins 'sacking up' the rest of the net to get the catch into a very tight long sack at the side of the vessel. From the beginning of the net haul until brailing, it takes nearly $2 \mathrm{~h}$ ( 110 min). The catch is then brought on board via a brailer. The brailer is a large dipnet that is lowered into the sack to scoop up the fish on top of the sack. It is then loaded onto the vessel and released into a system of chutes that funnel the catch into the holds below decks with a super-cooled brine solution. The number of brails required to get all of the fish on board depend on the size of the school. The brailing procedure from first brail until the last brail takes 18 min on average.
Editorial responsibility: Stylianos Somarakis, Heraklion, Greece
Submitted: June 20, 2014; Accepted: October 8, 2014 Proofs received from author(s): February 5, 2015 